\title{
Effectual Thinking: A Systematic Approach for Teaching Entrepreneurship as Part of Design and Manufacture Lab
}

\section{Dr. Sangarappillai Sivaloganathan, United Arab Emirates University}

Dr Sivaloganathan is an Associate Professor at the United Arab Emirates University and is the Program Director for the MSc in Engineering Management. He is an eminent researcher in Design Theory and Methodology and has published more than 70 papers in reputed journals and conferences. His research interests are Design Theory and Methodology, CAD and Applied FEA.

He graduated from the University of Srilanka in 1976. After an year of post graduation training in the Railway Workshops he joined the Cement industry where he worked for ten years. He got his M.Sc. from University of Aston in 1981 and Ph.D. from City University London in 1991. He joined Brunel universityin 1995 and worked there as a senior lecturer until he left Brunel in September 2011 to join UAEU. Dr Sivaloganathan was the founding Course Director for M.Sc. in Advanced Engineering Design at Brunel.

\section{Rajesh Ganithi, UAE University}

Mr Rajesh Ganithi started his career in engineering with a Diploma in Tool and Die Making from NTTF, India in 1995. In the next twenty years he has gathered enormous amount of experience and exposure while working in various companies in various capacities in various countries. He started his work with IRS Singapore Pte Ltd as mould maker for five years from 1995. He joined Meridian Automotive systems, Canada in 2001 as Tool and Die maker. In 2005 he joined ATS Automation Tooling Systems, Canada as Tooling Engineer. He joined Prolink Molds Canada in 2008 as Manufacturing Engineer. Training students in CNC applications was part of his work in the last few years in Canada. In 2012 he joined UAE University as Engineer in-charge of the CNC lab. The lab was completely rejuvenated by Rajesh and he plays an active role in teaching and researching CAM and its applications. Coming from a practical background Rajesh has research interests in strategies for machining time reduction and material saving. 


\title{
Effectual Thinking: A Systematic Approach for Teaching Entrepreneurship as Part of Design and Manufacture Lab
}

\begin{abstract}
:
A methodology to achieve the course outcome 'Students demonstrate an appreciation for entrepreneurial opportunities relevant to design and manufacturing' as part of the Design and Manufacture Lab course was needed. Drucker defines entrepreneur as a person who shifts economic resources out of an area of lower and into an area of higher productivity and greater yield. Looking at the literature suggests different approaches for teaching entrepreneurship. From these an approach that supplements engineering education from the perspective of the student who concentrates on science and engineering and whose primary interest is in technological innovation, was chosen. Effectual thinking focuses the thought process on the several technologies and knowledge components (means) lying around, to identify goals that can be achieved with these means. This thought process 'the means are here what are the causes or requirements' termed 'Effectual Thinking' was taught to students and they were engaged to explore applications of NC machine tools to identify entrepreneurial opportunities. The students took part with enthusiasm and studied the characteristics of a horizontal and a vertical machining centre before entering into effectual thinking. They employed the development of an engineering memorabilia item as the candidate product for exploration. They identified that the power and ease of programming and the availability of low cost tools of small diameters with long life pave the way for 3D nesting a new application to NC machine tools, which adds value to NC machine tools. Though it would take a long way to establish and prove the effectiveness of 3D nesting, effectual thinking was useful as a systematic method for identifying entrepreneurial opportunities.
\end{abstract}

Keywords: Effectual Thinking, Teaching Entrepreneurship

\section{Introduction}

An undergraduate program consists of several courses and each course is designed to achieve certain Course Outcomes that cater for the Student Outcomes of the program. Normally the Course Syllabus document outlines the course description, textbook, topics covered, course outcomes, assessment methods and details about the instructor. Understanding the document is easy for the student as well as for a new instructor who has to deliver the course. This is because the topics covered are sections of the subject and the course objectives are to gain competence in these topics. But the process becomes ambiguous when the course is an integrated one with no prescribed textbook and the syllabus is more generic in nature as in the case of the Design and Manufacture Lab course. The responsibility now falls in the hands of the instructor to devise experiments and projects (instructional activities and materials) to achieve the course outcomes. Whetton [1] stated that most important professing of a professor involves his thoughtful choice of reading materials, assignments, activities and most of all learning objectives. This is pronounced even more in this course because the instructor has to choose few experiments and a project from a wide variety of mechanical engineering applications. The objectives, instructional activities and material and the assessments he develops have to be in alignment. Students at the United Arab Emirates University normally complete their Bachelor's Degree in Mechanical Engineering in ten semesters. They take the Design and Manufacture Lab course, Mech 440, in the $7^{\text {th }}, 9^{\text {th }}$ or $10^{\text {th }}$ semester. They go for their industrial placement during the $8^{\text {th }}$ semester. One of 
the student outcomes, SO12, of the program is 'A recognition of the need for and an ability to engage in entrepreneurial activities'. The course Mech440 has nine course outcomes and one of them is 'Students demonstrate an appreciation for entrepreneurial opportunities relevant to design and manufacturing' which is mapped to achieve SO12. The challenge is to devise the instructional activities and materials to get the students to enthusiastically participate in achieving this objective. This paper describes how this course outcome has been achieved through a mini-project and the lessons learned.

\section{Literature Review}

Drucker [2] represents innovation and entrepreneurship as purposeful tasks that can be organized as systematic work. He states that innovation is the specific tool of entrepreneurs, the means by which they exploit change as an opportunity for a different business or a different service. He further asserts that innovation can be learned and practised. He argues that innovation endows resources with a new capacity to create wealth. Referring to J.B. Say, Drucker defines entrepreneur as a person who shifts economic resources out of an area of lower and into an area of higher productivity and greater yield. In other words innovation can endow manufacturing machine tools a new capacity to create wealth with reference to design and manufacturing. Singh [3] defines entrepreneurship as the process of creating something different with value by devoting thenecessary time and effort, assuming the accompanying financial, psychic, social risks andreceiving the resulting rewards of monetary and personal satisfaction and independence. The definition identifies (i) the creation process (ii) devotion of time and efforts and (iii) assumption of risks, as the main features. Duening and Sherrill [4] analyse the approaches to entrepreneurship education and identify six such approaches. They are

i. Business plan approach

ii. Resource based approach

iii. Entrepreneurial Mind-set approach

iv. Case-study approach

v. Simulation experience approach

vi. Entrepreneurial personality approach

They describe that business plan approach is taken by educators who believe that, development of a business plan is the most important feature of entrepreneurship. They found that 78 out of 100 top universities offered courses in business planning and take up the business plan approach. They list the primary goals of this approach as to teach the students (i) how to write a compelling business plan (ii) how to conduct market and industry research (iii) how to develop financial projections and (iv) how to integrate the various perspectives on the business concept.

Resource based approach holds that successful entrepreneurs are those who are able to gather and exploit resources with essential characteristics that they are (i) rare (ii) valuable (iii) hard to copy and (iv) difficult to substitute. It helps the students to understand that entrepreneurship is fundamentally a gathering and application of existing resources in new ways. Drucker [2] says that this application in the new way can make something worthless upto this point, into a valuable resource and thus entrepreneurship can create resources. This approach is more close to the engineering students.

The entrepreneurial mindset approach is designed to develop a way of seeing opportunity that is resident within a market. It is assumed that the various tools taught would provide the would-be 
entrepreneurs with a fresh set of insights into how markets behave. McGrath and MacMillan [5] identify the following traits as characteristics of entrepreneurs.

- Creating a climate supporting continuous search for opportunity

- Framingor defining goals

- Stocking an opportunity register or developing a rich set of potential opportunities to choose from.

- Focus or limiting downside exposure until the upside potential of the opportunity is demonstrated.

- Promoting adaptive executionor planning with discipline to the next major milestone, then pause and re-plan as new information becomes available.

Case studies approach follows the case study route in management like corporate finance and business ethics. The simulation experience approach creates a scenario that resembles a real world entrepreneurial experience. They are designed to address some of the process-oriented skills that are required. The entrepreneur personality is based on the assertion that entrepreneurs have distinctive personality traits that others can learn. Wilfing etal [6] identifies the big five personal traits of successful entrepreneurs.

Having thus seen the views and approaches to entrepreneurship the question is which approach would be more suitable for engineering students as part of a Design and Manufacturing Lab course. Cassel [7] states that the courses should be approached from the perspective of the student whose primary interest is in technological innovation, concentration is on engineering and science courses, and who has little or no prior business education. He argues that the courses have to be designed to supplement the student's engineering education. He then describes a course that investigates the knowledge and skills needed to recognize and seize an entrepreneurial opportunity and then launch a company.

Saraswathy [8] forwarded an innovative thinking called 'Effectual Thinking' which can systematize the search for Entrepreneurial Opportunities. From an engineering perspective it is normal for a societal need and its requirements are identified by the marketing sector. They are then refined as a set of final requirements for a new product. Thoughts are then focussed to fulfil this set of requirements. This is 'causal thinking' towards achieving an effect or goal in which the means are planned, arranged and combined to achieve the requirements. If now there are no requirements or set causes to focus the thought process, and there are several technologies and knowledge components (means) lying around, the challenge is to identify goals that can be achieved with these means. This thought process 'the means are here what are the causes or requirements' is termed 'Effectual Thinking' by Saraswathy. Effectual Thinking, which is the inverse of causal thinking, is the nucleus of entrepreneurship since this can identify new smart ideas. A systematic effectual thinking methodology involves:

i. Choosing the technologies or means that have to be put under scrutiny

ii. Carrying out trials to understand the entire characteristics so that the technology and engineering can be used to its best advantage

iii. Starting reverse mapping or effectual thinking to identify goals or entrepreneurial opportunities after understanding the capabilities of the technology.

Consider an example explained in three parts. 
Part 1 - An Interesting Feature of a Technology: When a beam of X-rays zaps a sample material it will cause other X-rays to be generated. These generated X-rays have energies that are characteristic of the atomic number of the atom in which they were generated. Thus by measuring the energies of the X-rays the elements they came from can be told. If the energies are measured under carefully controlled conditions and count the $\mathrm{X}$ rays from each element over a period of time, say 1 minute, the composition of the sample can be identified [9]. This is the development of science and technology. According to Saraswathy's effectual thinking method this is a means available for which a goal use is needed.

Part 2 - A Requirement in the Industry: Traditional manufacture of cement starts with excavating limestone and clay which are inter-ground to a powder called raw meal. The raw meal is burnt in the kiln to form clinker and grinding clinker with 3-5\% of Gypsum gives ordinary Portland cement. Clinker is a mix of complex silicates of Calcium, Aluminium and Iron and these are found in the raw materials limestone and clay. Efficient cement manufacture requires good control of the constituent elements in the raw meal. Traditional cement manufacture did not have facilities to measure the constituents fast and accurate for on line feedback control. When the raw meal is prepared in a raw mill, hourly samples are taken and analysed for controlling Calcium Carbonate content only. Based on the results corrective measures are taken. The ground raw meal is stored in a homogenising silo that blends the material thoroughly. Thus the control of the proportion of the constituents is limited to controlling the carbonate or Calcium content only.

Part 3 - Opportunity to Use X-ray to find the Composition of Raw Meal: Use of X-ray diffraction method can identify the constituents of the raw meal in a matter of couple of minutes. This lends itself for use as part of an on-line feedback control system. This is an entrepreneurial activity, which is the result of effectual thinking on the use of the means, x-ray, identified in part 1. This opportunity can be systematically identified by the effectual thinking method. In the cement industry this use has eliminated the need for homogenising silos and brought in the use of iron ore as the third raw material to produce better quality cement. The net effect is the saving of millions of dollars and better quality cement. In the process the x-ray analysis has gained more value due to a new application.

Effectual thinking thus can be very useful in identifying entrepreneurial opportunities in manufacturing and for that the technical details of the means should be known in full detail.

\subsection{Choice of Approach}

The literature identifies six different approaches for educating entrepreneurship. Out of these, resource based approach is identified as the one close to engineering students. Engineering students need to realize that they can easily identify the opportunities if they keep their minds in the 'Polling Condition' (refers to basically anything that periodically checks (polls) for data or a condition). However it needs a clear understanding of the capabilities of the science or technology they are considering. This is a difficult concept to grasp and it was felt that students have to actively engage in (i) learning to identify the capabilities and (ii) using the identified capabilities in a novel way to make something that is otherwise not considered valuable to gain more value. Other five approaches though are valuable could not be taught as part of a course with eight other learning outcomes. Effectual Thinking was chosen as the systematic method to engage the students in (i) learning to identify capabilities and (ii) using the identified capabilities 
in a novel way. The objective was to realize the course outcome Students demonstrate an appreciation for entrepreneurial opportunities relevant to design and manufacturing. The following sections describe how the problem was set and what results have been achieved.

\section{The Problem Formulation}

Department of Mechanical Engineering at UAEU has two machine labs, one with conventional machines and the other with numerical control machines. In the NC machines lab there are four groups of machines (i) bench lathes with FANUC controllers (ii) Boxford Bench mills with a special controller and CAM software (iii) a three axis Cincinnatti Vertical Machining Centre with Heidenhain controller and (iv) a horizontal machining centre with Seimens controller. NC machines have been in use for several years and the students have learnt the use of them in another course called Introduction to CAM. They can write programs manually or generate the code through the CAM package MasterCAM. NC machines have earned a certain level of reputation in the manufacturing arena through their capabilities including the quality of the work. The question has now been formed to read 'Is there a novel application of these machines that could make them more valuable and pave a way for an entrepreneurial opportunity'. The students were given a lecture and notes on effectual thinking. They were given an additional opportunity to produce a component and observe the capabilities of the machines. They were then requested to identify the special feature(s) and design a product that would exploit this feature in its manufacturing process. They were given a shaft of $50 \mathrm{~mm}$ diameter from which they could manufacture the product. The component given to them for trial manufacturing is shown in Figure 1.
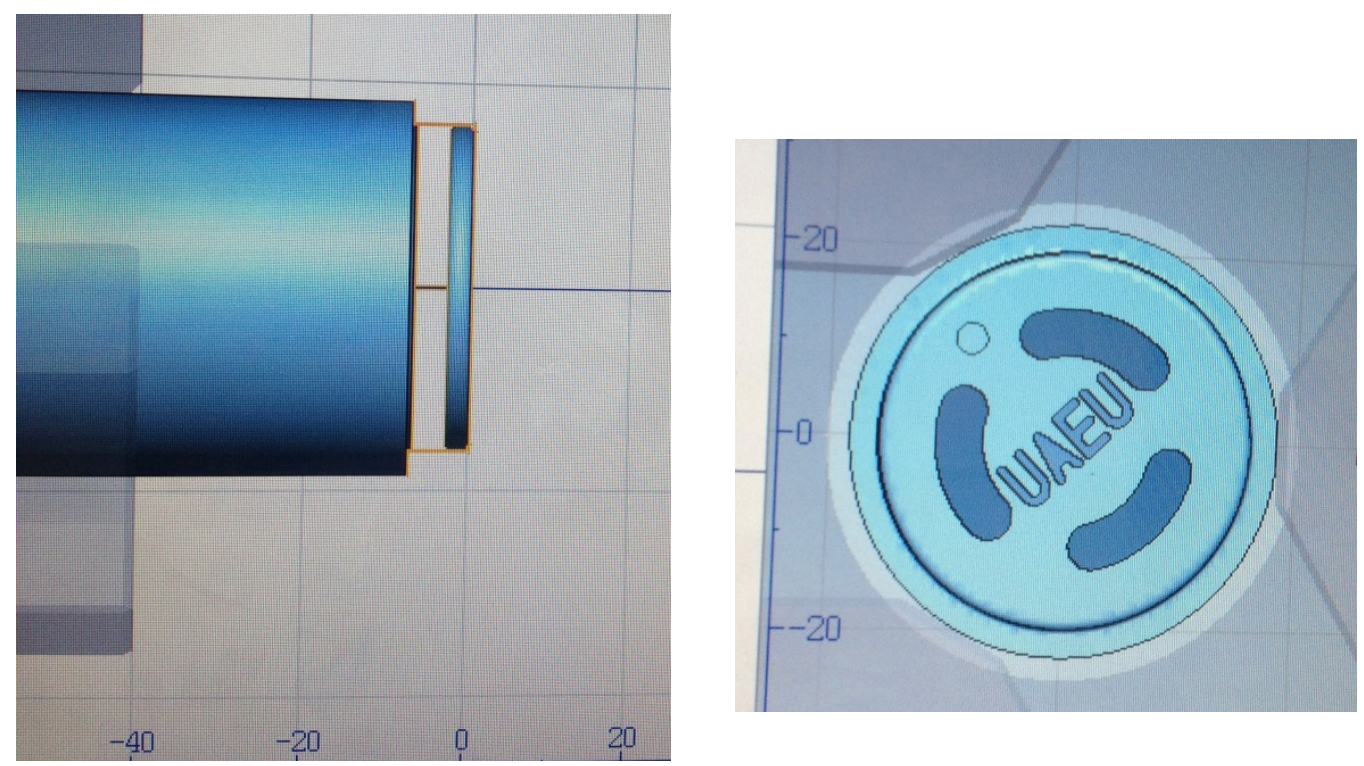

Figure 1: A Key-ring Disk, Component for Trial Manufacture

This component has some fine curves and the requirement was to have fine surface finish. Two machining centres were compared. Though it was not explicitly agreed or declared the students were working for some high quality memorabilia items that sell in the high end of the market. 
They were particular that the items should reflect some engineering concepts or mechanisms. Therefore their observations were directed towards the machining of finer geometric details with the trial component. In this sense the product they were making, a keyring disk shown in Figure 1 , was very appropriate. They analysed the possibilities of using the Vertical Machining Centre and the Horizontal Machining Centre in detail. The vertical machining centre uses MasterCAM to generate the machining code. MasterCAM in general requires a solid model built using CAD software like Solidworks or CATIA. The model can be built using MasterCAM itself but the process would be very difficult for complex shapes. They estimated that it would take about 2 hours of work. The horizontal machining centre has a feature-based facility to input the geometry or features to be manufactured. The software then generates the code.The exercise with the trial component showed them how the machining features were input to model the entire piece part. After careful analysis of both machines they decided to use the feature-based machine that took about 25 minutes to program the work. From this exercise the students have made the following observationsas the important ones that could be applied in making machined memorabilia items:

i. CAM software needs a CAD model built elsewhere if the product is complex.

ii. Feature-based machine was more easy and less time consuming to program.

iii. The horizontal machining centre has the milling ability and as such it could be used for combined turning and milling operations.

iv. In both machines parting-off requires a special tool and this inevitable operation consumes a significant portion of material when dealing with thin disk-like items turned from raw material shaft.In the trial component the disk was $5 \mathrm{~mm}$ thick but to part off another $4 \mathrm{~mm}$ of the work piece was lost.

v. Cutting tools with small diameters like $2 \mathrm{~mm}$ had significant life and they were relatively inexpensive. They can be used in manufacture of complex shapes with small amount of material loss.

With these observations the students were convinced that they could identify a novel machining combination thatwould enable the machining of engineering related memorabilia using $\mathrm{NC}$ machines.

\section{Design and Manufacture of the Memorabilia Item}

The students had brainstorming sessions and listed down items that could be manufactured by Machining. Several ideas were discussed. The following are some of them:

i. Shape designing scissors

ii. Cookie cutters

iii. Clocks

iv. Mobile phone covers

v. Door handles

These are some of many things that they can possibly do and start a business on and eventually make money as well. But it did not make use of any special feature that makes the NC more valuable than before. It is not entrepreneurship. It is at this stage the momentum was gained. They all agreed to design a keychain disc that would be unique for engineering related persons and sell easily. They sketched many different models individually and all came together and as a team chose a sketch. The key chain was designed in a way that it is made of gears enclosed in a 
box, but the box covers would have design cuts so the person can see through the holes and be able to see the gears and how they move. An initial design is shown in Figure 2.

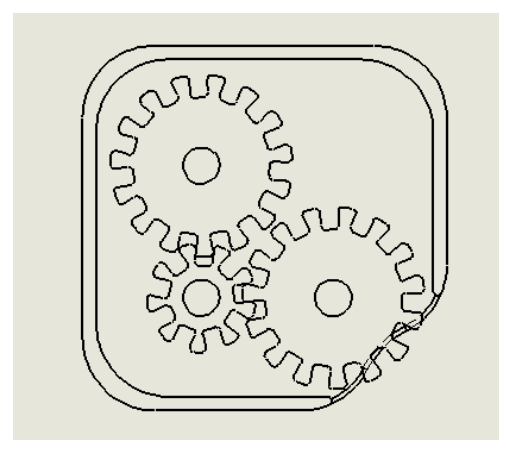

Fig 2: Initial Design

Although the concept was bringing forward engineering and thus is innovative, it was not making the best out of the machines. During a brainstorming session one of the students suggested making holes on the casing and small cuts on the wheels that change as the gears are turned. This exploited the small cutting tools to the full. They decided to engrave a face on the cover and the holes would be the eyes and mouth. The design was frozen. It is unique enough having enough complexities bringing out engineering features. Figure 3 shows the design.

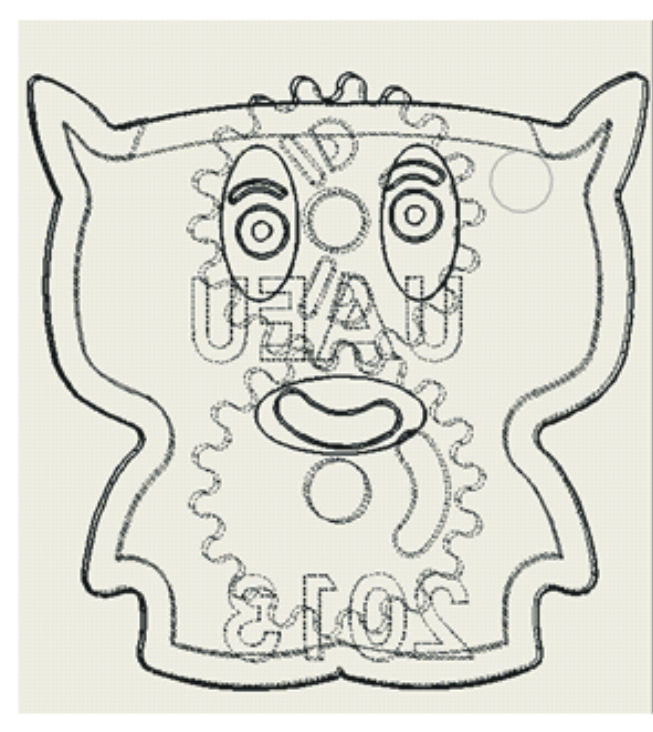

Assembled View

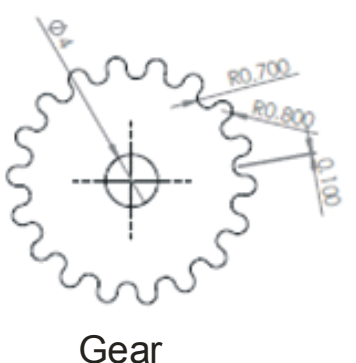

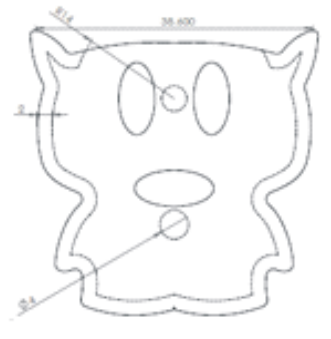

Front Plate

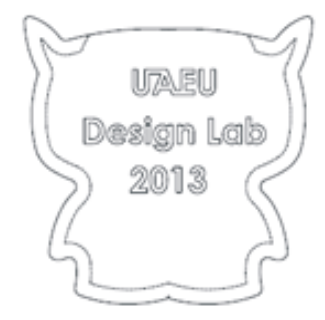

Back Plate

Figure 3:The Design

Now a unique way of manufacturing that (i) uses the special features of the machines (ii) consumes less material and (iii) made in short time has to be found. The design was complex and with many features of small dimensions. It is possible and easy to design it in Solidworks and transfer the design and use MasterCAM if the Vertical Machining Centre was chosen for manufacture. The piece could also have been made in the Horizontal Machining Centre using 
features. The clever idea came with the nesting. Nesting of blanks is a technique used in sheet metal work but seldom it is used in machining. The blanks were nested inside a circle on a piece of paper exploring the plan. This uniquely used the ability of (i) feature based machining (ii) CAD/CAM software and (iii) the ability of the cutting power of smaller diameter tools. This makes the process unique and value adding. The manufactured nesting is shown in Figure 4. It was made in the vertical machining centre. But it would have been possible with the horizontal machining centre too.

The main advantage of nesting is that all the parts required for an assembly could be machined from single work piece in a single setting. If the parts are of different thickness the reference for the thickness need to be at the parting-off line as shown in Figure 5. After machining is done, parting off operation in the same setting separates the machined parts from the stock, which are ready for assembly.

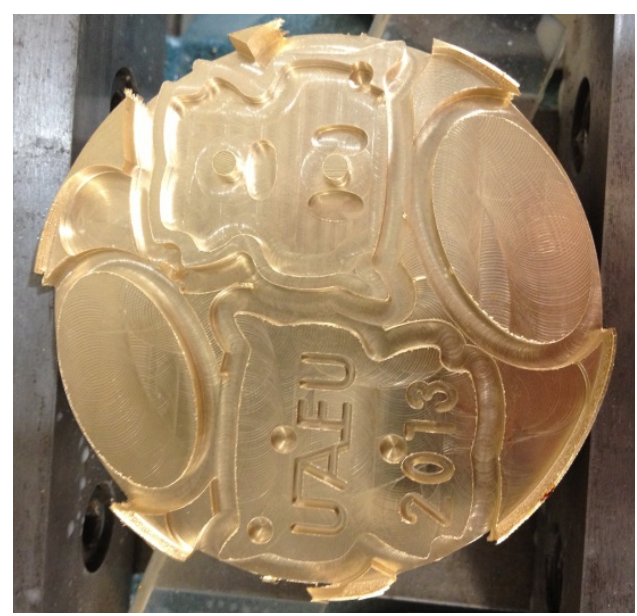

Figure 4: Nested parts inside the Shaft (Before Parting off)

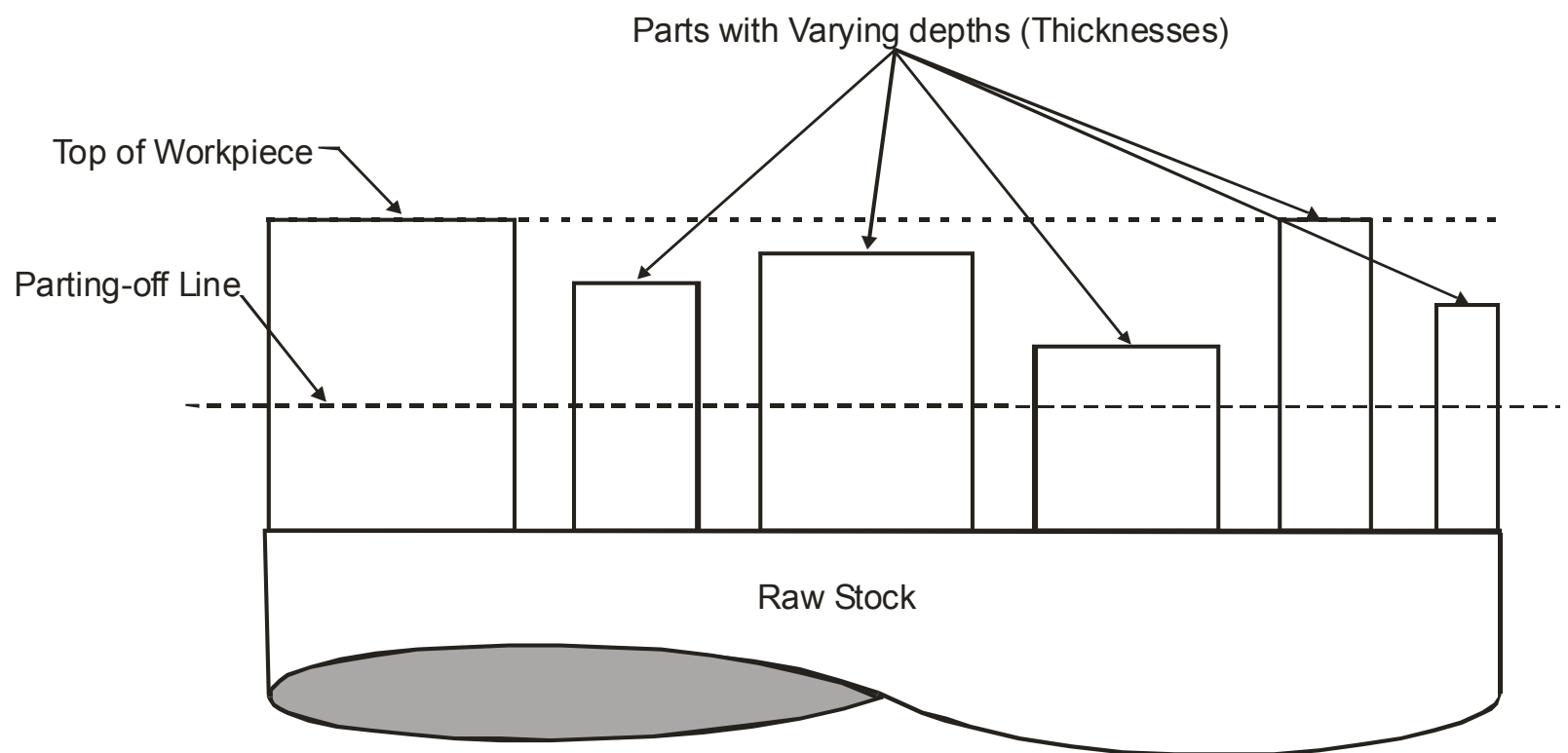

Figure 5: Parts with varying depths (thickness) in nesting 
The pieces were then cut off from the raw stock and the finished parts are shown in Figure 6. The assembled views are shown in Figure 7.

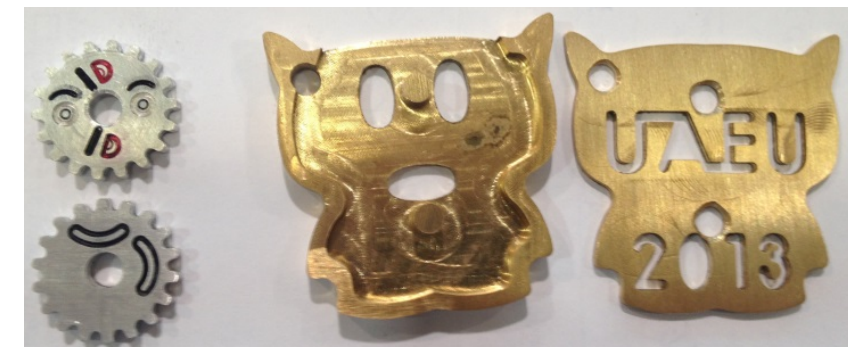

Figure 6: Finished Parts for the Product
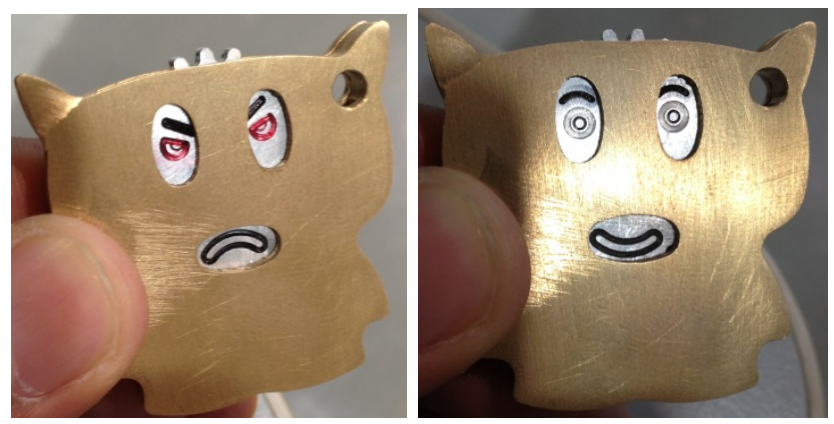

Figure 7: The Assembled Views

\section{Analyses and Discussion}

The desired course outcome from this project is 'Students demonstrate an appreciation for entrepreneurial opportunities relevant to design and manufacturing'. Drucker [2] said that innovation is the specific tool of entrepreneurs and Singh [3] said that entrepreneurship is the process of creating something different with value. Following these the project was intended to make students understand that entrepreneurship is fundamentally a gathering and application of existing resources in new ways. The NC machine tools, an existing resource was taken as the candidate to demonstrate this and therefore the hypothesis was 'Innovation can endow manufacturing machine tools a new capacity to create wealth with reference to design and manufacturing'. Effectual Thinking, the search for goals achievable by a given set of means, was the approach taken to test the hypothesis. The method applied consists of two stages (i) identifying the specialist strengths of the resource that is to be used and (ii) establish a specific application in which to apply the resource in a novel way to solve the problem. Considering the $\mathrm{X}$-ray analyser example these can be translated as (i) identifying the ability of X-ray diffraction to establish the constituents and (ii) identifying the constituents of the raw meal as the specific application of the capability. In the project a candidate example in machining was used to establish the capabilities of the machines. Through this example the students identified the strengths of the two machining centres, which are the resources for which novel applications and resulting value addition are sought. The second stage was divided into two parts in this project. 
In the first part the students identified a memorabilia item reflecting an engineering application, which was chosen as the area for business, and a design was created reflecting this. In the second part the specialist features of the machines were used in a novel way to make the manufacturing viable. The generic method is shown in Figure 8. It is made up of four stages.

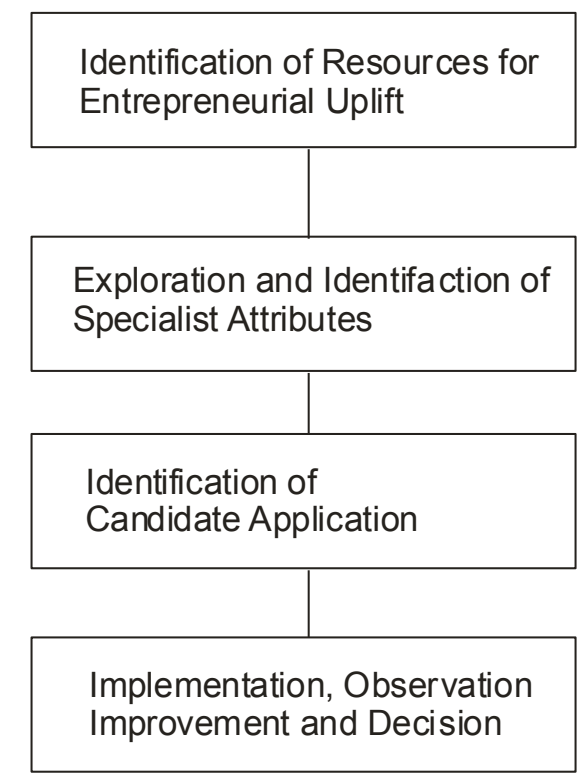

Figure 8: Effectual Thinking Model to Identify Entrepreneurial Opportunities

Identification of the Resource for Entrepreneurial Uplift - This can be any manufacturing process such as investment casting, water jet cutting, NC machining, TIG welding etc.

Exploration and Identification of the Specialist Attributes - Opportunity for innovation lies with the unutilized specialist feature and therefore the success of the method relies on this step.

Identification of Candidate Application - The candidate application only adds value to the process. It is like the composition analysis of the cement raw meal adding value to the X-ray diffraction method in the example. In the case of the project the candidate application should be a design needing the specialist features for its realisation. At this point it is worth remembering the assertion by Duening and Sherrill [4] 'that successful entrepreneurs are those who are able to gather and exploit resources with essential characteristics that they are (i) rare (ii) valuable (iii) hard to copy and (iv) difficult to substitute'.

Implementation, Observation, Improvement and Decision - The chosen specialist attributes of the technology were used, tested and observed at this stage and any improvements needed are also carried out at this stage. At the end a decision was made whether it is a true entrepreneurial opportunity that can yield results. 
Analysis of the project in accordance with the model is given Table 1.

Table 1: Analysis of the Project According to the Effectual Thinking Model

\begin{tabular}{|l|l|}
\hline \multicolumn{1}{|c|}{ Stage } & \multicolumn{1}{|c|}{ Work in the Project } \\
\hline $\begin{array}{l}\text { Identification of Resource } \\
\text { requiring Entrepreneurial Uplift }\end{array}$ & $\begin{array}{l}\text { This is a decision that has to be taken by the senior } \\
\text { management of a company. However in this case the } \\
\text { decision was based on the availability of the technology } \\
\text { for students to experiment and explore. The NC } \\
\text { machines chosen are real production machines and thus } \\
\text { mimic a real-life situation. }\end{array}$ \\
\hline $\begin{array}{l}\text { Exploration and Identification of } \\
\text { the specialist attributes. }\end{array}$ & $\begin{array}{l}\text { The exploratory experiment was a good one with many } \\
\text { features with small dimensions with minute details. } \\
\text { They demanded long operations that exhibited the } \\
\text { strengths and features of the cutting tool. The students } \\
\text { have identified five specialist attributes, which they used } \\
\text { in the next stage. }\end{array}$ \\
\hline Identification of Candidate & $\begin{array}{l}\text { This was a tricky one where the students felt that there } \\
\text { is a need for memorabilia items reflecting engineering. } \\
\text { Then they have to com-up with a candidate design, } \\
\text { which is only one of the several possibilities. The } \\
\text { candidate should be a design consisting of typical } \\
\text { features that reflect engineering. The design was a mood } \\
\text { changing cat with a gear driven mood change. }\end{array}$ \\
\hline $\begin{array}{l}\text { Implementation, Observation, } \\
\text { Improvement and Decision }\end{array}$ & $\begin{array}{l}\text { Only part of this stage could be realised with a student } \\
\text { was functioning as expected. However improvements } \\
\text { and fine tuning can be made to improve appeal. } \\
\text { Decision is beyond the scope of this course. }\end{array}$ \\
\hline
\end{tabular}

\subsection{Learning Experience of the Students}

The student groups were too small and inexperienced for any efforts like the protocol study. Instead they were asked to record their experiences under two headings namely (i) team dynamics and (ii) learning experience. In the team dynamics they recorded the enthusiastic participation of the team members and how the final design and the manufacturing method evolved. The enthusiasm and involvement were very much evident in this section. The learning experience section described their feelings and emotions with the project. They have recorded the thrill of systematically exploring a manufacturing process. To quote "We have honestly learned more things in this one course than we did during our whole university life. In every course there is always a professor or Doctor who tells you how the future is going to be and what we should be ready to handle but unfortunately they do not implement it. It's very hard to learn by words but easy to learn by experience. In this class 'design and manufacturing lab' we actually learned what team work and time management means. We learned how to compromise and discuss matters as if we were all company division managers. We learned to get over many of the different challenges. We learned what is entrepreneurship in a systematic way." 


\section{Conclusions}

The first and foremost conclusion that could be drawn is that Effectual Thinking can be employed to systematize the thought process for identifying entrepreneurial opportunities arising from a scientific finding or technology. To train students in an activity, a systematic model of that activity is fundamental. The four-stepped methodology used in this project works satisfactorily to achieve this.

Three-dimensional nesting is an exciting prospect identified in this project. This has to be further investigated to understand its potential and limitations. The nesting of blanks with same thickness is relatively easier than nesting of blanks with varying thickness. This is an interesting research area.

The five specialist characteristics identified by the students are individually simple and straight forward but when combined in applications they open up interesting opportunities.

References:

1. Whetten D.A. Principles of Effective Course Design: What I wish I had Known About Learning-Centred Teaching 30 Years Ago, Journal of Management Education Vol 31 No 3, June 2007 pp339-357.

2. Drucker P.F., Innovation and Entrepreneurship, Harper Collins Publishing, New York 1986.

3. Singh R.K. Management study material rajeshsingh_r_k@rediffmail.com

4. Duening T.N. and Sherrill W.W., Teaching Entrepreneurship to Engineers: A Logico Deductive Review of Leading Curricula, Proceedings of the ASEE Annual Conference June 2006.

5. McGrath R.G. and MacMillan I.C., The Entrepreneurial Mindset: Strategies for Continuously Creating Opportunities in an Age of Uncertainty, www.columbia.edu/ rdm20/emsumm.doc, Downloaded on $24^{\text {th }}$ December 2013.

6. Wilfling S., Cantner U. and Silbereisen R.K, Which Big Five Personality Traitsdrive entrepreneurial Failure in Highly Innovative Firms, DRUID-DIME Academy Winter Conference 2011.

7. Cassel T.A.V. Engineering Entrepreneurship at Penn, Proceedings of the ASEE Annual Conference June 2003.

8. Saraswathy S.D., What makes Entrepreneurs Entrepreneurial, University of Washington, 2003.

9. http://www.understanding-cement.com/analysis.html

The authors wish to thank the anonymous referees for their valuable contributions to improve the quality of the paper. 